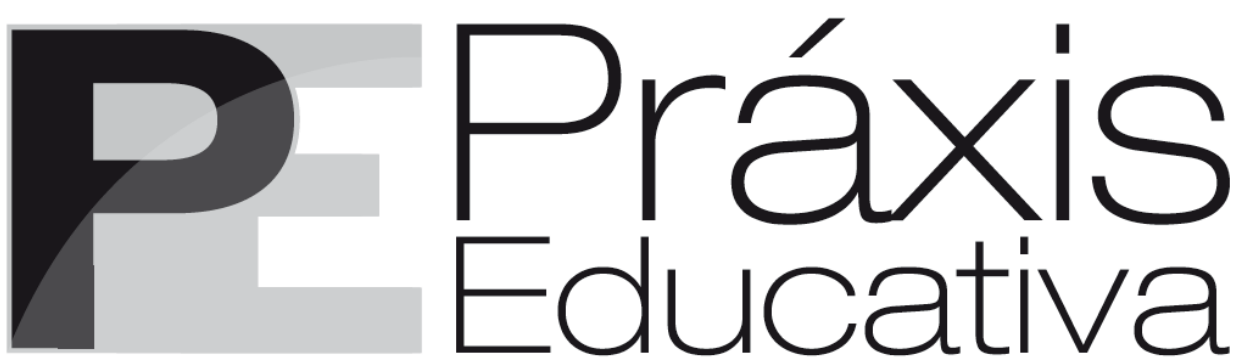

ISSN 1809-4031

elSSN 1809-4309

http://dx.doi.org/10.5212/PraxEduc.v.14n3.011

Apresentação

\title{
Dossiê: Jovens e ativismos em (des)construção: socializações e (in)ações políticas
}

\author{
Miriam Leite* \\ Vítor Sérgio Ferreira* \\ Valéria Floriano Machado ${ }^{* * *}$
}

A última década do século XX foi palco de criativas e (relativamente) inesperadas manifestações políticas, que seguem resistindo e insistindo, até os dias de hoje, na possibilidade de alternativas à ordem social imposta pelo neoliberalismo. Batalha de Seattle, Fórum Social Mundial, Occupy Wall Street, Escolarismo, Indignados, Geração à Rasca, Primavera Árabe, Revolução dos Pinguins, \#NeverAgain, Marcha pelas nossas vidas, ocupações estudantis na América Latina, manifestações em Hong Kong - mundo afora, muitas e diversas têm sido as recentes ações de contestação política que contam com expressiva participação de jovens e de estudantes de diferentes graus de ensino.

Práticas de contestação mais individualizadas e menos institucionalizadas tendem também a disseminar-se entre os mais jovens, em áreas como a alimentação, a energia, a habitação, a arte, a saúde, a orientação sexual, a identidade de gênero, entre muitas outras esferas dos estilos de vida. O movimento slow, o veganismo, a agricultura orgânica, os squatters são algumas expressões, entre muitas outras, do alastramento de novas formas de ativismo e de novos conteúdos políticos à vida cotidiana entre as pessoas mais jovens.

Quando organizados coletivamente, tendem a inovar em seus formatos, que, coletivos ou individualizados, imprimem dinâmicas organizacionais em que enfatizam o empenho na horizontalidade das suas relações e proposições; que se pautam pela relativa autonomia e mesmo resistência a partidos e outras instituições tradicionais na atuação política, como sindicatos e associações estudantis; e que se inclinam a usar intensiva e globalmente novas tecnologias de comunicação e redes sociais virtuais para disseminar as suas pautas e organizar ações públicas.

\footnotetext{
* Professora da Universidade do Estado do Rio de Janeiro - UERJ. E-mail: <miriamsleite@yahoo.com.br>. ORCID: http://orcid.org/0000-0003-3833-2150

** Professor do Instituto de Ciências Sociais - Universidade de Lisboa. E-mail: <vitor.ferreira@ics.ulisboa.pt>. ORCID: http://orcid.org/0000-0001-8080-9288

*** Professora da Universidade Federal do Paraná. E-mail: <vfloriano@gmail.com>. ORCID: http://orcid.org/0000-0002-3914-7144
} 
Inovam também em suas motivações, valores e objetivos políticos, atuando não apenas em lutas pelos direitos ao e do trabalho e da educação, mas também contra o racismo, pelo direito à cidade e à sua mobilidade, à educação, à saúde pessoal e ambiental, pelos direitos da mulher, da fluidez de gênero e das populações LGBTQI+, pela democracia radical e participativa, pelo reconhecimento da legitimidade da voz das pessoas jovens nas várias esferas sociais por onde vivem e circulam - entre outras bandeiras de mobilização que não necessariamente se articulam em torno a projetos pré-definidos de futuros sociais.

No entanto, nesse cenário, não deixa também de haver uma larga faixa juvenil politicamente pouco empenhada, desinteressada dos temas relacionados com a vida pública, o bem comum e a participação cidadã, e pouco ou nada mobilizada socialmente perante os novos desafios do futuro global. Esse tipo de configuração de atitudes entre os jovens é ainda, contudo, um tema pouco estudado pelos juvenólogos, para além da problemática relativa à abstenção juvenil na participação em atos eleitorais, tema caro aos cientistas políticos.

O forte interesse acadêmico pelos ativismos em detrimento dos inativismos juvenis é, uma vez mais, patente nas contribuições obtidas à chamada de artigos para o dossiê Jovens $e$ ativismos em (des)construção: socializações e (in)ações políticas. Buscando contribuir para a problematização desse quadro, o convite ao debate acadêmico em torno desses novos ativismos teve mais receptividade do que o debate acerca das amplas parcelas de jovens que não se engajam em tais movimentos e que, eventualmente, seguem aderindo a perspectivas políticas conservadoras. Quer a ausência desse debate, quer a ampla presença de estudos em torno da construção social de novas formas, pautas e espaços de socialização de ativismos juvenis, atestam a pertinência de tais discussões na atualidade.

Entre as muitas propostas recebidas, os 13 artigos e um relato de experiência que compõem esta publicação revelam a instigante pluralidade de pesquisas, com temáticas, enfoques teóricos e metodológicos diversificados, que vêm sendo desenvolvidas na aproximação acadêmica às questões do ativismo político e da cidadania entre as juventudes contemporâneas. Nesse painel, percebe-se que o movimento estudantil continua contando com importante espaço de pesquisa e problematização. Não apenas o movimento estudantil universitário (Groppo, Ramos, Trevisan, Abrão da Silva, Silveira), já com uma ampla tradição de ativismo político em vários países, mas sobretudo o movimento estudantil secundarista, relativamente emergente no panorama mundial dos ativismos juvenis.

A ênfase que o ativismo secundarista ganhou neste dossiê acaba por reproduzir o destaque que a sua forma expressiva distintiva tomou no espaço público mediático, por via das ocupações das escolas públicas por estudantes do Ensino Médio. Neste dossiê, vislumbra-se a espessura social desse fenômeno, na abordagem que é feita aos diferentes tempos e formas que foram assumindo no Brasil, bem como à heterogeneidade de pautas que foi tomando e de experiências proporcionadas aos seus vários participantes (Teixeira, Henning e Freitas; Pacheco e Nascimento da Silva; San Segundo e Severo; Borges e Dias da Silva; Pacheco e Sallas).

$\mathrm{Na}$ sua pluralidade, o fenômeno que as ocupações secundaristas representaram tem em comum, em grande medida, o fato de tornarem-se, elas próprias, contextos de socialização política pelas experiências de aprendizagem, de reflexividade e de prática ativista que proporcionaram aos estudantes que delas participaram, não se reduzindo ao papel de meros agentes reprodutores de processos de socialização política anteriores. É durante as ocupações que muitos estudantes de escolas públicas experimentam, pela primeira vez, a realização de uma ação ativista. Um ativismo que, ali, repensa e reclama não apenas uma nova escola, nas suas infraestruturas e relações e conteúdos propriamente pedagógicos, mas também uma ampliação das expressões juvenis para além do papel de estudante, onde haja também lugar à afirmação e à

Práxis Educativa, Ponta Grossa, v. 14, n. 3, p. 1004-1006, set./dez. 2019 Disponível em: <http://www.revistas2.uepg.br/index.php/praxiseducativa> 
existência de outros atributos subjetivos de identificação e expressão juvenil, relacionados ao gênero, orientação sexual, etnia, religião, culturas juvenis etc.

O destaque dado ao movimento estudantil e às ocupações de escolas públicas, neste dossiê, vem a par do reconhecimento e do interesse acadêmico por formas de ativismo político de outras populações juvenis em condições precarizadas e vulnerabilizadas, cujas pautas muitas vezes se cruzam. Falamos, por exemplo, do movimento Tarifa Zero, em Belo Horizonte (Moreira e Leão), que reivindicava o abaixamento do preço dos transportes públicos e, por essa via, o direito dos mais pobres e dos estudantes à circulação na cidade; ou de pautas relacionadas aos direitos de pessoas em condições de deficiência crónica (Venera, Albuquerque e Buriti), de jovens mulheres de periferias urbanas (Vargas e Saraiva) e o seu acesso aos empoderamentos feministas, ou de direitos exigidos pelas populações de jovens LGBTIQ+ (Couto Junior, Brito, Pocahy e Amaro).

Entre as discussões abordadas nos vários artigos, os contextos interativos mediados pelas redes sociais virtuais ganham relevo não apenas como contextos de participação na esfera pública, mas sobretudo como ambientes não institucionais de construção e de socialização de ativismos vários e ainda pouco institucionalizados. Abordam-se ainda outros contextos cronotópicos ou espaços-tempos institucionalizados de socialização e de participação política, tais como as associações ambientalistas (Cristo e Barzano), as associações escutistas (Rodrigues, Menezes e Ferreira) e grupos de criação artística (Garcia, Macedo e Queirós), além de se pensar o cotidiano da escola na formação das subjetividades juvenis (Napoli e Richter).

Entretanto, por entre a multiplicidade teórico-metodológica que acompanhou a diversidade temática dos artigos, observa-se que a ênfase na atenção à voz da pessoa jovem perpassa todos os estudos apresentados, muitos recorrendo a métodos participativos e de coprodução, quer no trabalho de elaboração dos projetos e de pesquisa empírica, quer na própria realização dos artigos, em que tradicionais interlocutores da pesquisa passam a assumir o estatuto de seus colaboradores ou até mesmo seus coautores, intervindo ao longo das suas várias fases. Assume-se a pesquisa como processo social no qual pesquisadores e entrevistados traduzem, em texto acadêmico, as experiências vividas nos contextos de ativismo juvenil. Assim, temos a satisfação de afirmar que, neste dossiê, não se tratou a experiência política juvenil sem dialogar com seus sujeitos.

No mais, esperamos que as reflexões trazidas a público nesta coletânea sigam provocando outras pesquisas e indagações sobre as ações e as inações da juventude na contemporaneidade.

Editores convidados

Práxis Educativa, Ponta Grossa, v. 14, n. 3, p. 1004-1006, set./dez. 2019 Disponível em: <http://www.revistas2.uepg.br/index.php/praxiseducativa> 